\title{
A Case Study of Enterprise Application Integration Based on Workflow Management System
}

\author{
Baosen Yang and Lu Liu \\ Department of Information Systems, School of Economics and Management, Beihang \\ University, Beijing 100083, P.R. China ybs@buaa.edu.cn liulu@buaa.edu.cn
}

\begin{abstract}
Work flow management system (WFMS) is a flexible tool for enterprise application integration (EAI). The EAI implement with work flow technology is cheap and convenient. This enlarges the view of enterprises and gives them an opportunity to integrate their legacy applications by advanced IT technology. By study on environment and stratagem of enterprises, this paper establishes a solution of the EAI based on work flow management system and presents an EAI framework with an embedded workflow management component to support business-to-business operations. Nowadays, however, such system is not common. A case study of EAI implement in Tianjin Port is presented and a brief overview of the current enterprise applications and information systems in this enterprise are also presented.
\end{abstract}

Keywords: EAI, Work flow management system, Enterprise systems, Virtual enterprises

\section{INTRODUCTION}

Most of enterprises in China have stepped on the Nolan-Stage IV: integration of information systems. Business organizations today face a complex and competitive environment. E-commerce is becoming more dynamic. It is now termed open Ecommerce [1]. Different enterprises put their services and resources together so that they appear to be virtual enterprises (VE) [2]. The relationship between members is thus different from that within a traditional enterprise, because the members are independent, constituent, and dynamic and the business process is scattered over multiple enterprises and subject to frequent change. However, the agility of a company's response to customer demand has been recognized as a critical success factor in meeting competition.

This implies that a cross-enterprise information system is imperative. It should aim at implementing interoperability among independent enterprises, smoothing the information flow between them, and reforming business processes over multiple enterprises. To satisfy and respond quickly to the requirements, many companies are now focusing on enterprise application integration (EAI) in order to strengthen their ability to compete. This has therefore been recognized as an important area for IT innovation and investment [3]. 
Workflow is the automation of a business process. It has now been adopted as a way to implement the cross organization management needed to carry out businesses. The internet's world-wide web has become the prime driver of contemporary electronic commerce (E-commerce). Phan [4] holds the view that the most successful new business models are probably those that can integrate IT to all activities of the enterprise wide value chain.

\section{EAI AND WFMS}

\subsection{EAI: Enterprise Application Integration}

Enterprise application integration namely EAI aims to make more than one legacy system in enterprise connected each other by IT so that all systems can cooperate mutually, sufficiently share and use the information resources and eliminate the existing isolated island of information from enterprise.

The traditional EAI adopts the way of peer to peer connection to realize electronic data exchange. But some large enterprise usually owns many application systems. Some of these systems may be old and the other may be new so the integration of them is very complex, difficulty and expensive. This makes enterprise seek new way to solve the problem.

\subsection{WFMS: Work Flow Management System}

Conventionally, business processes were implemented by hard-coding embedded into the organization's software systems. This led, however, to inflexible systems that were hard to modify and maintain. Work flow is a technology that addresses such problems by separating and abstracting business processes from the software systems [5]. It is the automation of a business process, during which documents, information, or tasks are passed from one participant to another for action, according to a set of procedural rules [6]. A WFMS is used to define, create, and manage the execution of work flows through the use of software running on one or more work flow engines. The engines can interpret the process definition, interact with work flow participants, and, where required, invoke the use of IT tools and applications. Work flow has now become a leading tool in modeling enterprise business rules by taking advantage of continuous advancements of IT. Its inherent characteristics make it suitable to implement cross organizational management. Unfortunately, today's work flow management systems are generally designed to support the work flow within one business unit rather than between business units. Moreover, those from different vendors have problems in cooperation [7]. Thus, a committee, the WFMC, is working on standards for workflow interoperability. The WFMC has focused on developing a variety of interoperable scenarios that can operate at a number of levels from simple task passing to full work flow interoperability. 
However, the real issue is not to connect systems but to develop fundamentally new concepts and architectures to support inter-organizational work flow. When developing an information management system for Tianjin Port Petrochemicals Terminal Company (TPPTC), we developed an inter-enterprise work flow architecture that used the internet. The main part of the architecture was a workflowsupported internet information system and an integrated interface.

\section{A CASE STUDY}

In this section, a case study conducted at Tianjin Port Petrochemicals Terminal Company (TPPTC) investigating the implementation of EAI is discussed. The case study starts with introducing the company and its background, presenting the current status of IT and giving the detail scheme phase of the implementation of EAI in TPPTC. Also, the research methodology is discussed.

\subsection{The Background}

Tianjin port is the biggest artificial harbor in China. It is a very important international port in north China and is the gateway of capital Beijing to ocean. Also it is the nearest to the inland of north China and north-west China in Bohai bay. Tianjin Port Petrochemicals Terminal Company(TPPTC) backing on the biggest harbor in north China_- Tianjin port, by means of the vast inland, convenient and swift transportation, perfect facilities and other advantages has established the good cooperative relationship with numerous petrochemical enterprises. The throughput, oil storage, delivered amount and trade amount have increased quickly in near three years. It is gradually becoming an important trade and distribution center of petrochemicals in north China.

\subsection{IT at TPPTC and Analyzing}

During the period of "the 10th five-year program of development" TPPTC information system construction had got supports strongly from Tianjin Port Group Company and the infrastructure of IT became advanced. Currently, the state of network and hardware is as follows:

By now TPPTC has invested 6 million $¥$ to purchase 5 computers as servers, 125 computers as workstations so that every manager has one computer at least. There is a $1000 \mathrm{M}$ fiber cable to connect with Tianjin Port Group Company. Also there is a local area network to connect every office and there is a virtual private network for middleclass managers to connect interior server from outside of his or her office.

Since 1998 especially 2003 based on database management systems TPPTC have successively developed and put to use 20-30 applied information systems, such as human resource management, finance management, facilities management, 
measurement management, safety management, freight transportation management, customer management, office automation, administration management, file management etc. After investigating and analyzing the status quo of TPPTC information architecture, we think that there is some characteristics and problems as follows:

- Vertical Applications

Most of applications are vertical applications which the functions are set for the superior company Tianjin Port Group Company and few applications consider the business requirement of TPPTC itself, for example:

The scheduling system and freight transportation system is portion of Tianjin port business management system. They can provide the forecast of freight, the month plan and the information of distribution, but they can not provide the key management means of TPPTC: five-day scroll plan and other necessary statistical reports.

The other systems such as human resource management, finance management, facilities management, measurement management, safety management etc. are similar and all belong to vertical applications.

- Poor Integrality

There is no uniform organization model, no uniform user management model and no uniform foundation data in the existing information system. The foundation data include data of human, machine, material, method, environment etc. The fields of existing information systems are divided according to organization not business process, so the data format in a system is much different from another, for example:

Every system has a set of authority policy and if a user wants to use more than one set of information system he or she must remember each account in each system. This is not benefit to access the information safely.

- Isolated Island of Information

All existing information systems own independent database respectively so they can not share data and cooperate with each other. The designer of existing information systems are absent in thinking of integration and cooperation, so the mechanism of integration is also absent and the need of enterprise cooperative business can not be satisfied, for example: the information of freight and charge must be repeat inputting in finance department after production department has done.

- Lacking of Restriction of Standards

Almost 30 information systems are running in TPPTC but there is no uniform design criterion and IT standards. Most of them were designed in Client/Sever architecture. This makes the farther development of information system in TPPTC embarrassed and the IT management has a trend of decentralization.

- No uniform user interface

The legacy applications were developed in deferent periods and there are deferent styles of user interface and operation way. This makes the users feel difficulty to learn and use. Although the legacy applications may provide many functions to users, but the users may give up since they can not easily control the computers, for example, some legacy applications have developed for long time but have not put them into practice yet now. 


\subsection{The Target of EAI in TPPTC}

With above analyzing, we conclude that:

The future Information System Platform of TPPTC is to be established as a business management and network information platform for all employees, customers and outer authorized users of TPPTC. The platform is based Internet/Intranet/Extranet and is real time, integrated, interactive. Through electronic business gateway according with electronic commence standards TPPTC can share and exchange its data with Tianjin Port Group Company, administration, customs and partners. Then the virtue information system will be built and the logistics information, trade information and currency information etc. can pass easily across the whole petrochemical supply chain.

\subsection{EAI based on Work Flow Management System (EAI-WFMS)}

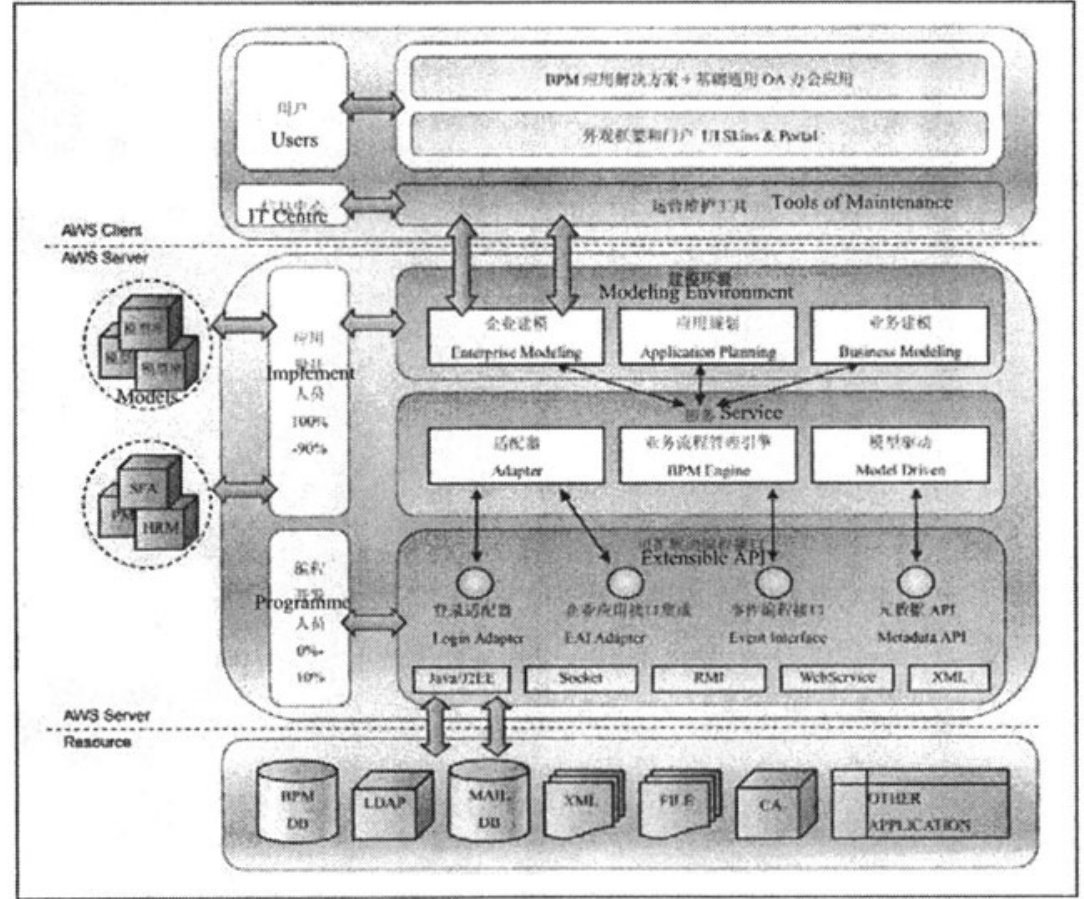

Figure 1. The Architecture of EAI Based on Work Flow Management System

The technology of EAI-WFMS comes from Actionsoft Company (ASC). AWS Enterprise is a product of WFMS based on JAVA/J2EE and is a multi-layer web application oriented to model driven. The modeling tools provided by AWS 
Enterprise can realize $90 \%$ of zero coding for complex requirements. Through the programmed interface the integration ability can satisfy diversified requirements. Figure 1 shows the architecture of EAI based on AWS workflow management system.

\section{5. Illustration of Integration}

U8 is ERP software of User Friend Company. The employee inputs the data of expense account by AWS Enterprise and when selecting the item of expense, the corresponding category of general ledger can be drawn out off U8 finance management system. Then U8 can keep debited and credited accounts.

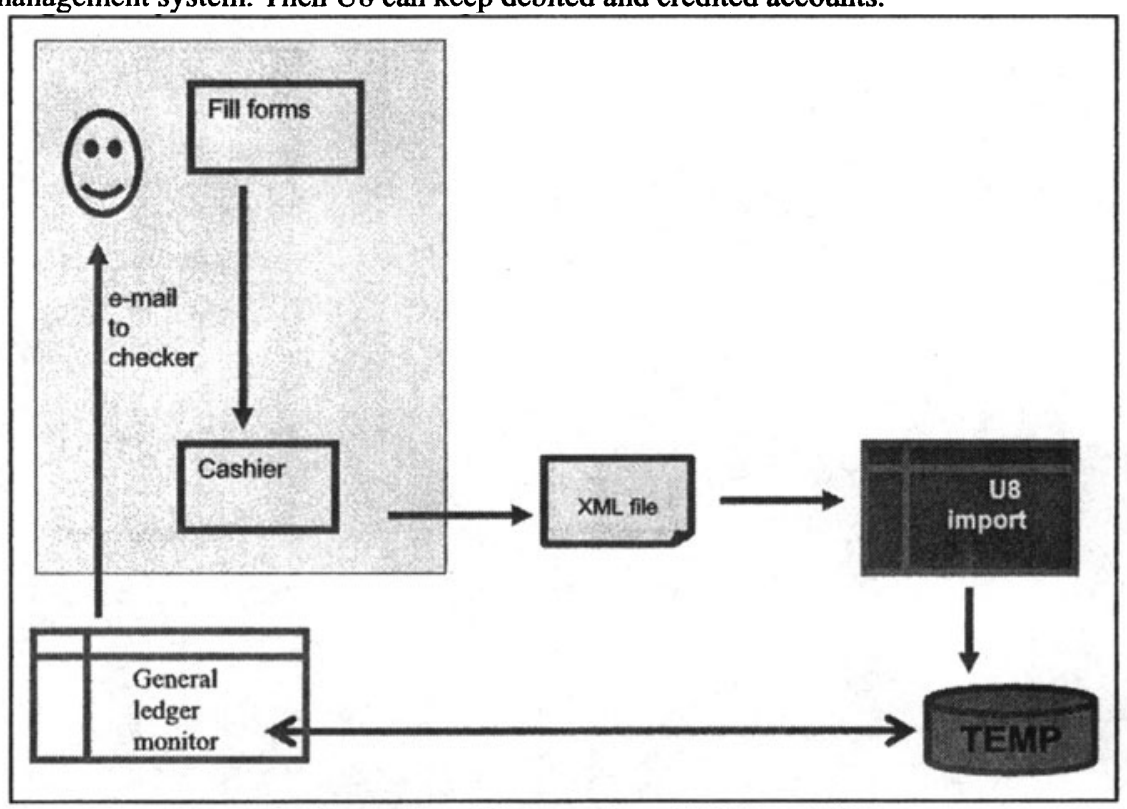

Figure 2. Illustration of Integration of AWS and U8

\section{SUMMARY}

The EAI project workgroup was made up of a management team of specialists from the external outsourcing company Actionsoft Company (ASC). ASC also have the specialized talents of EAI consultants. The project workgroup consisted of specialist internal managers and staff that had vital knowledge of cross-functional business relationships and experience of the old internal systems. The project construction cycle is about 3 years (from 9/2006 to 12/2008). EAI implementation team has understood the business, cultural and technical difficulties of such a large project. The team has used the specialist skills of consultancy specialists. The 
partnership has produced a sound architectural framework for the project, thus allowing TPPTC to concentrate its efforts on production and safety management. A project of this size would never run smoothly and difficulties have occurred throughout the implementation and will no doubt occur in the future.

\section{ACKNOWLEDGEMENTS}

The research is supported by the National Natural Science Foundation of China under Grant No.70671007 and the $\mathrm{PhD}$ Program Foundation of Education Ministry of China under Contract No. 20040006023.

\section{REFERENCES}

1. W.M.P. Van Der Aalst, Loosely coupled interorganizational workflows: modeling and analyzing workflows crossing organizational boundaries, Information and Management. Volume 37, Number 2, pp.67-75, (2000).

2. G. Dimitrios, S. Hans, C. Andrzej, and B. Donald, Managing process and service fusion in virtual enterprises, Information System. Volume 24, Number 6, pp.429-456, (1999).

3. J. Bowersox and J. Calantone, Logistics paradigms: the impact of information technology, Journal of Business Logistics. Volume 16, Number 1, pp.65-68, (1995).

4. D. Phan, E-business development for competitive advantages:a case study, Information and Management. Volume 40, Number 6, pp.581-590, (2003).

5. M. Kradolfer, A Workflow Metamodel Supporting Dynamic, Reuse-based Model Evolution. Ph.D Thesis, University of Zurich (2000).

6. A. Rob, Workflow: An Introduction, WfMC (1999). http://www.wfmc.org/standards/docs/Workflow_An_Introduction.pdf (Accessed May 4, 2007)

7. W.M.P. Van Der Aalst, Process-oriented architectures for electronic commerce and interorganizational workflow, Information Systems. Volume 24, Number 8, pp.639-671, (1999). 